\title{
Research on copyright protection of WeChat
}

\author{
Han Jiashan ${ }^{1, a}$ \\ ${ }^{1}$ Tianjin University of Science and Technology, China \\ atust_han1993@foxmail.com
}

Keywords: WeChat, Copyright, The path to explore

\begin{abstract}
Since the coming of the era of media, which makes the copyright protection is not only confined to the print media industry, the copyright protection of the network environment is also nots allow to ignore. This article we take WeChat—-the representative of the Internet revolution in China as the breakthrough point, first of all, through the data to demonstrate WeChat copyright protection, For WeChat point and object, Copyrights protection ground, contents and relief has carried on the deep discussion and definition. Secondly, this paper discusses the WeChat manifestation of copyright infringement, determination and responsibility, and from WeChat characteristics, copyright belong to determination and tort compensation and cost problem three aspects proposed the WeChat copyright protection. Finally, from the legislation, the network service providers, WeChat public number, the copyright owner and the reader's rights and obligations set out to put forward to solve copyright dilemma path to explore. Need five parties together for build respect WeChat copyright, WeChat copyright protection atmosphere, for WeChat copyright of building green and healthy environment.
\end{abstract}

\section{Introduction}

We-Media is an emerging thing under the rapid coverage of the Internet. With the popularity of smart phones and the use of microblog, WeChat and other software, We-Media era is moving towards a rapid development track. According to the latest data released by authorities, the number of Internet users in the world has exceeded 3 billion, and the number of Internet users in China has reached 600 million, among which the number of users who surf the Internet through mobile terminals has reached 500 million, accounting for $88.9 \%$ of the total number of Internet users. Mobile terminal has become the preferred bridge between users and the Internet. Users publish their own content through the mobile Internet to form their own unique works, and then spread through the Internet to spawn new works. The mobile Internet has become an important medium and channel for copyright transmission.

In January 2011, Tencent launched a new smartphone chat tool -- WeChat. WeChat supports voice chat, video sharing, picture transmission, etc. It provides forwarding, group chatting, friend circle and other functions, and consumes a very small amount of network traffic. Since then, WeChat has become a leader in intelligent terminal applications.

\section{The need for WeChat copyright protection}

\subsection{Features of WeChat}

WeChat's rapid development momentum prompted tencent to launch a new platform model -WeChat public platform -- a year later with low threshold, strong interactivity and great freedom. It has the following communication characteristics: 1. Information communication mode: point-to-point. When the user successfully focus on a public account, and select after receiving the information sent to the public accounts that can be sent via a single, mass and other ways to convey information to WeChat users, WeChat public platform of information transmission, and the traditional print similar way of dissemination of information, and WeChat than the traditional print media and increase the good interactive. 2. Transmission process: low noise interference. On WeChat public platform, the transmission process noise between user and public account is less interfered 
based on the point-to-point communication mode, which is more conducive to enhancing the communication effect. Audience: real. WeChat requires the account to be tied to the phone number one to one, and every WeChat user is real.

\subsection{The need for WeChat copyright protection}

With the advent of the we-media era, copyright protection is not limited to the print media industry. WeChat transmits information across operators and systems platforms through voice, text and pictures, and integrates the features of "instant and social" and its "micro-storm effect". While building a communication platform, it also puts forward the dilemma of copyright protection.

WeChat is not only an innovative mobile application, but also a representative of China's Internet revolution. The rapid development of WeChat also brings a series of dilemmas of copyright protection of WeChat. It can be seen from the relevant data in WeChat production white paper released by WeChat that with the further expansion of WeChat public account and service number, control of copyright infringement of WeChat is imminent.

\section{Relevant theoretical problems of copyright of WeChat}

\subsection{Object problem of copyright of WeChat}

Copyright belongs to the category of intellectual property, which refers to the author's legitimate and lawful rights to create works in the fields of art, literature and science. The copyright of WeChat platform refers to the collective name of copyright owners' property rights and personal rights of protected works on WeChat platform subject to the provisions of the copyright law. The copyright of WeChat platform involves roughly the same content of rights as the traditional copyright content stipulated by the copyright law, both including the personal and property rights of the copyright owner.

The copyright under the platform of WeChat is a new form of copyright under the development of times. WeChat users can be divided into two categories: individual users and public accounts. For these two types of users, the emphasis of copyright is also different. For public accounts, works published by public accounts shall not infringe others' copyright. For individual users, information related to the account and content reprinted in the circle of friends shall not infringe others' copyright. In the WeChat platform, as long as the published content conforms to the intellectual achievements of the original and reproducible authors, and can be fixed through some tangible material carriers, and can maintain a relatively static state in relative time, such works should be identified as the object of copyright in the WeChat platform

\subsection{Acquisition time and protection time of WeChat copyright}

Many of the work on the WeChat platform is improvisation by the authors, with the convenience of smartphones and WeChat apps. According to China's copyright law, works of Chinese citizens, legal persons or other organizations, whether published or not, enjoy copyright in accordance with China's copyright law. Therefore, the content published by Chinese citizens on WeChat platform, which conforms to the definition of works under the copyright law, already enjoys the copyright when the creation is completed. For the release of contents of the public account of WeChat platform, it involves works which are owned by legal persons or other organizations in the identification of works on duty. According to the provisions of China's copyright law, the publication period of the works is 50 years and the deadline is December 31 of the fifth decade after the works were first published on the public platform of WeChat. According to the copyright law of China, the publishing right of photography works published by individual users has a term of protection of 50 years, which is up to December 31 of the fifth decade after the work was first published on WeChat platform. 


\subsection{WeChat copyright content issue}

China's copyright law concerns the protection of the personal and property rights of Chinese citizens and organizations. Personal rights include the right of authorship, the right of publication, the right of alteration and the right to protect the integrity of works. Property rights include distribution rights, reproduction rights, exhibition rights, rental rights, projection rights, performance rights, broadcasting rights, information network transmission rights, adaptation rights, translation rights, etc. Since the rapid development of media technology, all kinds of information is available on the Internet to upload and download, this model can easily make the works of the copyright owner of the public spread via the Internet, network drive, the tort form more changeable, the copy rights of the copyright owner and information network transmission right is put forward a great challenge. The fast coverage of WeChat is particularly important for the discussion of these two rights in the WeChat platform.

When the copyright law was revised in 2001, the concept of "information network transmission right" was added. As for the confirmation of the right of information network transmission, China believes that the public can freely choose the place and time to contact the right of the work by providing the work to the public through wired or wireless means. First, the subject of information network transmission right is the copyright of works and two types of adjacent right holders (performer and producer of audio and video). Secondly, the right of information network transmission only limits the interactive communication behavior, that is, "the public can contact the works at any place or time". Third, the restriction of information network transmission right is directed to the public.

Property right is an important part of copyright, which plays a very important role in determining the scope of right of reproduction and protecting the legal rights of the right holder. If the scope is too narrow, the legal rights and interests of the copyright owner will be infringed. Too wide a range can harm the public's reading and use of the work. According to the provisions of China's copyright law, the right to reproduce is defined as the legal right to fix a work in accordance with the law on a tangible carrier by means of copying, printing, reproducing, recording and digitizing. The main elements of reproduction rights are as follows: first, reproduce the original works. That is, can be copied through the prevention of new copies of the original. On the WeChat platform, it mainly refers to the digital form mentioned in the reproduction right, and refers to the reproduction of the original works in the digital form saved through computer related technologies. Second, the copy is fixed in a tangible form. In other words, the work can maintain a relatively static state in the reconstructed tangible carrier for a certain period of time. On WeChat platform, the forwarding of works can be preserved. Third, copying is not original. In micro letter platform, if the author while doing ZuoQuanRen forward original works by adding a work way of original ideas for work, this copy behavior does not constitute a copy, and on the premise of not ZuoQuanRen copyright infringement original, the organizer has to organize new works, the copyright of a work has obtained the consent of the author, on the consolidation process, the new work exercise their rights of authorship, etc.

\subsection{WeChat statutory disclaimer}

The aim of China's copyright law is to ensure a good creative environment and further flourish the cultural industry. Therefore, when the copyright law of our country defines the right scope of the right holder, it also limits the right of the right holder to guarantee that the work can be used and spread reasonably.

Traditional print media environment, limited by work mode of transmission, copyright infringement is relatively small, the obligee's rights protection is also strong, into the network era, especially in WeChat widely used, the form of the works by the print media to electronic media, transmission form transmitted by print into share, forward propagation, the rights of the copyright owner of the more vulnerable to abuse, based on this, explores the legal liability of the WeChat setting problem is particularly important, WeChat legal liability problems mainly involve the fair use and statutory license system of the two. 
Article 22 of the copyright law of China points out 12 cases of reasonable use and application. The cross-border nature of WeChat platform based on Internet weakens the copyright exclusivity, and the specific application should be recognized. For example, in the Internet environment, non-commercial use of government policies aimed at popularizing the public, such as the Chinese government network, can be used reasonably.

With regard to statutory licensing, China's copyright law mainly provides six statutory licensing conditions. The regulations on the protection of the right to disseminate information on the Internet indicate that published works do not enjoy the legal permission. Without permission, published works shall not be uploaded on the Internet. Otherwise, the right to disseminate information on the Internet will be violated. Therefore, public account platforms such as WeChat can be identified as sites referred to in the regulations. Most public account platforms are profit-oriented and do not apply to specific situations where reasonable use is required, but operators of public account can use certain works without authorization in compliance with legal provisions, but need to pay remuneration.

\section{Copyright infringement of WeChat}

\subsection{The manifestation of copyright infringement}

Information released to Wechat users of most of the existing information involves network, or from journals, newspapers, books, television and other traditional print information, if released in micro letter platform of the information belongs to the identified by the copyright law works, you need to consider to obtain permission from and pay remuneration to the copyright owner in accordance with the problems that might involve copyright infringement problems. The information publisher of WeChat may infringe the copyright owner's right of information network transmission, modification, alteration, protection of the integrity of the work and the right of authorship. User's reprint behavior, the reprint behavior of WeChat public platform may cause infringement of copyright owner's reproduction right, information network transmission right and other legal rights.

\subsection{Identification and liability of copyright infringement}

At present, the contents of WeChat copyright infringement in Chinese courts are roughly the same as those in traditional copyright infringement identification. It mainly involves the identification of the object of copyright and the constitutive elements of infringement of the right of duplication and the right of information network transmission.

To determine whether the contents published by WeChat platform infringe copyright. First, to determine whether the contents released belong to works protected by China's copyright law, that is, to identify the object of WeChat copyright mentioned above. If the elements needed to constitute a work can be considered as published content protected by China's copyright law. Secondly, in the environment of WeChat, it is necessary to determine whether the copyright owner's right of information network transmission and reproduction is infringed. When determining the constitutive elements of information network transmission right, it is necessary to judge whether it can be considered as reasonable use or is within the scope of legal license. At present, China's current legislation does not regulate the right of reproduction too broadly, and does not involve the issue of temporary reproduction. Based on this, the current reproduction use of WeChat does not involve the identification of temporary reproduction. According to the current laws and regulations, the statutory license only applies to six circumstances, and the reproduction on WeChat platform and other behaviors do not belong to the statutory license scope. When judging whether infringement, above all, can exclude the application of legal license system. Secondly, to determine whether the infringement is within the range of reasonable use and whether it meets the four elements mentioned above. Sharing information with friends or acquaintances is fair use. However, public accounts of WeChat are mainly for commercial purposes and cannot be deemed as reasonable use. The corresponding WeChat users can obtain the works of public account in free place and time, which conforms to the constitutive elements of information network transmission right, and the reproduction of WeChat 
public account constitutes the infringement of the copyright owner's information network transmission right. For WeChat platform itself, WeChat platform are not responsible for copyright infringement in principle, but in the infringement of copyright owners to WeChat platform feedback works be after WeChat platform need to take relevant measures to guarantee the legitimate rights and interests of the copyright owner, if WeChat platform for failing to take the necessary measures to control the infringement, will need to bear tort liability. The function of forwarding exists in WeChat, which can be used by ordinary users. The forwarding behavior should be considered according to the standard of reasonable use. For the copyright owners who publish works in WeChat, it is necessary to understand this function. If they do not want the works to be Shared by others, they should make it clear in the works. If they do not make it clear, it is deemed as acquiescence and consent to others' forwarding. If the forwarding activity of others is for non-commercial purposes and does not bring losses to the copyright owner, it can be deemed as reasonable use; otherwise, it constitutes infringement. When found himself works copyright violations of the copyright owner and supported by evidence, micro letter platform adopt corresponding technical means shall be informed to stop the infringing act, if micro letter platform take timely technical means to stop the behavior, can adapt to the principle of safe haven, that micro letter platform according to the meaning of the copyright owner of the hindered the expand the activities of the infringement behavior that has occurred, the micro letter platform therefore does not constitute infringement; On the contrary, if WeChat fails to respond to the claim of the copyright owner, it shall bear indirect tort liability. In particular, when the infringement of the rights of the copyright owner is obvious, the WeChat platform cannot excuse the liability of the copyright owner for failing to appeal, but the red flag principle applies to determine that the WeChat platform bears the liability of indirect infringement.

\section{The dilemma of copyright protection of WeChat and its resolution}

\subsection{The plight of WeChat copyright protection}

\subsubsection{The characteristics of WeChat lead to the proliferation of torts}

The communication mode of WeChat leads to the occurrence of infringement. The communication mode of WeChat is point-to-point fragmentation transmission, which emphasizes complete static rules in the traditional copyright protection. The legislator, by building a complete copyright protection system, has a clear pattern to solve the various processes of infringement from generation to the end. However, in the network environment, this mode is broken, and users have the initiative to disseminate works. In particular, mobile application platforms such as WeChat push the mode of fragmentation to the extreme. Every mobile phone and every user's behavior may have a transmission effect. The overall transmission of information is transformed into the transmission of small networks. In this way, the infringement is more difficult to control.

WeChat sharing failure leads to infringement. WeChat mainly involves three kinds of sharing behaviors: sharing among friends, sharing in moments and public account push. The first is the behavior of sharing works between friends, which refers to the information sharing behavior between users added to each other as friends in WeChat. WeChat friends from QQ friends, contact list friends and shake. Limited number, no more than a few hundred people, sharing to friends individual or group sharing behavior, may lead to infringement. The second is the user through the circle of friends to share the work behavior, by the user to install plug-ins, circle of friends can be real-time release content and browse friends post information, transmission range is limited to the number of friends, friends with thumb up and comment function, does not support the forwarding function, is not easy to the spread of a massive, but users can copy and paste, and open the link sharing way transmission, copyright infringement may occur. The third is the behavior of the public account to push the works to users. Users can contact related works through receiving the broadcast of relevant news terminal and the push of the public account concerned. Unauthorized reprint of public accounts can easily cause copyright infringement. 


\subsubsection{Difficult problem of ownership of copyright}

Users can release works on WeChat platform, mainly through the way of publishing works and signing works to protect their qualifications as the subject of copyright owners, that is, the rights of publication and the right of authorship. On WeChat platform, the phenomenon of reproducing a work without identifying the source of the work is abundant, and what's more, it is plagiarism to put your own name in other works. At the same time, the work is spread through relatively small closed circles on the WeChat platform, and the infringer has no technical means to accurately locate the infringing information. When the copyright owner discovers the infringement, the information publisher can quickly delete the record, and the copyright owner is faced with insufficient evidence. The massive existence of this phenomenon aggravates the occurrence and spread of the infringement, which makes the property rights and personal rights of the copyright owner cannot be guaranteed properly.

\subsubsection{Tort liability and cost}

The current legal procedure requires that the burden of proof should be paid to the notary office for real-time notarization when all the evidence of infringement is obtained. If the evidence is not notarized, after the infringer deletes the evidence, it will be difficult to Sue even if the copyright owner has screenshots and other evidence [14]. Fingertips a touch can share, the outcome of the copyright owner is an infringer effortlessly, right protection of the rights of the copyright owner need to notarial cost is too high, coupled with the micro letter platform of work need to spend more on copying identifying such as energy, even cost notarization fees shall be charged rights protection of the copyright owner for the compensation is also difficult to make up for losses, even not enough rights. Most copyright owners usually give verbal warnings or even take a silent attitude due to the difficulty of proof and high cost of rights protection. It is difficult for the copyright owner to protect his own legitimate rights and interests, which will greatly damage the enthusiasm of the copyright owner to create.

\subsection{The path exploration of solving the tort dilemma}

The third amendment to China's copyright law has been put on the agenda. The Internet industry and the traditional print media industry still have a stalemate in pursuing different demands on some related issues. Therefore, it can be seen that the copyright law tends to give priority to the protection of content providers, and the demands of the Internet industry still cannot be met. Taking WeChat as an example, this paper discusses some insights on solving WeChat infringement dilemma.

5.2.1 Legislation to improve the rights and obligations of the stakeholders in WeChat copyright

The copyright infringement problem caused by the rapid development of "we media" still lacks relevant rules to regulate in China's laws. In the draft for the third revision of the "we media" law, there are few involved in the copyright infringement. At present, the most pertinent documents for the regulations on the protection of communication information through network, determine the legal license, the reasonable use, copyright management techniques and principles, haven for copyright owners and Internet service providers, libraries, readers to distinguish the rights and obligations of, to further standardize the copyright protection in the network environment provides important legal support.

The law is lagging behind, and the legislative branch needs to adapt to the development of The Times, adjust the relevant social relations in a timely manner, and make a real-time response. By clarifying the internal legal relations of infringement on WeChat platform and the corresponding technical problems, establishing a complete legal order to regulate infringement behaviors; Establishing a strict accountability mechanism for infringements. Specific needs to consummate the following two aspects, first, solves the jurisdiction confusion situation, the clear jurisdiction provision. As the server and computer terminal and other equipment are relatively fixed when the infringer conducts the infringement, the location of the server and computer terminal can be identified as the place of the infringement. Second, improve the loss calculation standards and establish a complete punitive compensation mechanism. To combat WeChat copyright infringement, should stipulate infringement behavior person double compensation for loss caused by infringement of the copyright owner and the infringer profits, therefore, in addition, the infringer shall also 
compensate for the cost of the direct expenditure in stopping the infringement of copyright, including the notarial fees, transportation and other expenses.

\subsubsection{The rights and obligations of Internet service provider (Tencent)}

The early copyright law mainly aimed at the paper media industry to provide institutional guarantee. The copyright law gives certain rights to the creator of the work, but the dissemination of the work is controlled by some commercial organizations, and the creator of the work needs to authorize the disseminator in order to gain profits from the dissemination of the work. The early copyright is actually controlled by the owner of the copyright industry. With the emergence of the network, the communication mode has been further innovated. Through providing users with interfaces and platforms, the network service providers realize the operation of the business mode by relying on the scale of users.

Tencent, the technical support party of WeChat, should be classified as an online service provider. As a provider of the platform, tencent is also engaged in profit-making activities, and should shoulder the obligation to protect the rights of copyright owners. Network service providers shall undertake the following obligations: first, supervision obligations. Tencent should provide technical support for the healthy development of WeChat platform by improving relevant technical measures and issuing relevant management rules and other supervision methods. Second, delete obligations. Tencent should, after receiving the notice of infringement from users, manage the infringement in a timely manner, delete the information of suspected infringement and prevent the expansion of the damage result. Otherwise, it shall bear the corresponding compensation liability for the extension of the loss. Third, close account obligation. After receiving notification from users, tencent conducted a review of copyright infringement activities on the WeChat platform, closed accounts for accounts with actual infringement, and suspended network access services for a period of time.

Meanwhile, tencent needs to strengthen responsibility awareness, strengthen self-monitoring channels, develop new technical support, achieve more convenient monitoring and ensure the legality of information dissemination on WeChat platform. Meanwhile, the real name registration mechanism and information disclosure mechanism should be improved to cooperate with judicial protection.

\subsubsection{WeChat public account's rights and obligations}

The copyright infringement involving WeChat public platform mainly depends on whether the content published by public account is suspected of infringing the copyright of the right holder. The public account of WeChat shall apply for the authorization of the copyright owner when publishing the content, and shall not make profits without the permission of the copyright owner. Or when reproducing other people's content, indicate the place of reproducing and protect the copyright owner's right of authorship, and pay corresponding remuneration in time. Meanwhile, we will actively cooperate with the copyright protection measures of tencent and make use of the original declaration function of public account to protect the original declaration articles.

5.2.4 The enhancement of the consciousness of rights protection of copyright owners

For copyright owners who publish works in WeChat, they need to understand the forwarding function of WeChat. If they do not want their works to be Shared by others, they should make it clear in the works. If they do not make it clear, they will be deemed as acquiescing to others' forwarding. When the copyright owner finds that the copyright of his work is infringed and supported by evidence, he shall notify WeChat platform to take corresponding technical measures to stop the infringement. At the same time, in order to protect their legitimate rights and interests, they should do the following: firstly, they should understand relevant laws and regulations and the methods adopted by WeChat for copyright protection. When publishing articles on WeChat platform, use the original declaration protection strategy provided by WeChat to protect their copyright. Second, after the occurrence of infringement, we should not be passive and take the initiative to save the evidence at the first time. We should make a complaint through the tort complaint system of WeChat and submit the proof materials to ensure that the infringement can be stopped in time.

\subsubsection{Readers' awareness of copyright protection is improved}

Protection of copyright of WeChat should not only rely on external forces, as readers should also improve awareness of copyright protection. First of all, as readers, we should pay attention to their 
own behavior, fully understand the legal knowledge of copyright protection, learn the letter of the user agreement platform, and the standard of copyright protection, etc., understand the importance of copyright protection, prudent in hair, micro letter content, reasonable and lawful use of the work of others, to avoid unwittingly infringes on the copyright of others. Second, respect others' copyright achievements. As far as possible, we should pay attention to high-quality public accounts, read high-quality pushed articles, avoid infringing copyright by plagiarizing others' works and other copyright-infringing behaviors, do not do the promotion, and timely report to WeChat platform for complaint, so as to jointly maintain the good development of WeChat platform. Finally, when publishing contents on WeChat, we should improve our awareness of self-protection and take positive actions to prevent our works from being reprinted. When we suffer from infringement, we should not take a negative attitude and take the initiative to protect our rights.

\section{References}

[1] Liang Liu, Bo Qu, Bin Chen, et al. Modeling of information diffusion on social networks with applications to WeChat[J]. Physica A-Statistical Mechanics and Its Applications, 2018, 496.

[2] Chen Y, Liang C, Cai D. Understanding WeChat Users' Behavior of Sharing Social Crisis Information[J]. International Journal of Human-Computer Interaction, 2018, 34(3):1-11.

[3] Zhang Y, Li Z, Gao C, et al. Mobile Social Big Data: WeChat Moments Dataset, Network Applications, and Opportunities[J]. IEEE Network, 2018, 32(3):146-153.

[4] Yang xiaolan. Research on network copyright [M]. Intellectual property publishing house, 2012.

[5] Xiong qi. Reform of copyright rules driven by Internet industry [J]. Chinese law,2013,06:79-90.

[6] Yang yanchao. Research on copyright issues related to WeChat platform [J]. Intellectual property, 2015(8):47-52. 